\title{
Dielectric Elastomers UV-Cured from Poly(dimethylsiloxane) Solution in Vinyl Acetate
}

\author{
Seung Koo Park ${ }^{1, *(\mathbb{D}}$, Meejeong Choi ${ }^{1}$, Dong Wook Kim ${ }^{2}{ }^{\mathbb{D}}$, Bong Je Park ${ }^{1}$, Eun Jin Shin ${ }^{1}$, \\ Suntak Park $1, * \mathbb{D}$ and Sungryul Yun $1, * \mathbb{D}$ \\ 1 Human Enhancement \& Assistive Technology Research Section, Electronics and Telecommunications \\ Research Institute, 218 Gajeong-ro, Yuseong-gu, Daejeon 34129, Korea; jjeong0527@etri.re.kr (M.C.); \\ bjpark@etri.re.kr (B.J.P.); shin015511@etri.re.kr (E.J.S.) \\ 2 Advanced Materials Division, Korea Research Institute of Chemical Technology, 141 Gajeong-ro, \\ Yuseong-gu, Daejeon 34114, Korea; dongwook@krict.re.kr \\ * Correspondence: skpark@etri.re.kr (S.K.P.); spark@etri.re.kr (S.P.); sungryul@etri.re.kr (S.Y.)
}

Received: 20 October 2020; Accepted: 5 November 2020; Published: 11 November 2020

\begin{abstract}
Poly(dimethylsiloxane) (PDMS) has been extensively used as an electroactive polymer material because it exhibits not only excellent moldability but also mechanical properties sufficient enough for electroactive performance despite low dielectric permittivity. Its low dielectric property is due to its molecular non-polarity. Here, we introduce a polar group into a PDMS elastomer by using vinyl acetate (VAc) as a crosslinker to improve the dielectric permittivity. We synthesized a high-molecular weight PDMS copolymer containing vinyl groups, namely poly(dimethylsiloxane-co-methylvinylsiloxane) (VPDMS), and prepared several of the VPDMS solutions in VAc. We obtained transparent PDMS films by UV curing of the solution layers. Electromechanical actuation-related physical properties of one of the UV-cured films were almost equivalent to or superior to those of platinum-catalyzed hydrosilylation-cured PDMS films. In addition, saponification of the UV-cured film significantly improved the electrical and mechanical properties $\left(\varepsilon^{\prime} \sim 44.1 \mathrm{pF} / \mathrm{m}\right.$ at $\left.10 \mathrm{kHz}, \mathrm{E} \sim 350 \mathrm{kPa}, \varepsilon \sim 320 \%\right)$. The chemical introduction of VAc into PDMS main chains followed by saponification would offer an efficacious method of enhancing the electroactive properties of PDMS elastomers.
\end{abstract}

Keywords: elastomer; poly(dimethylsiloxane); photocuring; vinyl acetate; saponification; permittivity

\section{Introduction}

Poly(dimethylsiloxane) (PDMS) is widely known to be a fluid polymer even if it has a high molecular weight because the greater angle and higher length of the Si-O-Si bond in the PDMS main chains in comparison to the $\mathrm{C}-\mathrm{C}-\mathrm{C}$ bond make its chain motion free [1,2]. PDMS can be crosslinked and solidified mainly by a platinum-catalyzed reaction of vinyl groups with hydridosilyl groups in the main chains [2,3]. PDMS shows excellent moldability for those reasons. The vinyl or hydridosilyl groups can be introduced into PDMS by a copolymerization method. The vinyl group-containing PDMS generally has a higher molecular weight than the hydridosilyl group-containing PDMS which acts as a crosslinker. Since the two PDMSs are mechanically mixed together just before shape forming and thermal curing, the platinum-catalyzed reaction cannot uniformly occur during curing, resulting in heterogenous mechanical properties of the PDMS product. Nevertheless, PDMSs have been used as a shapable material for nanoimprint stamps, microfluidic chips, electronic skins, wearable sensors, and actuators owing to their transparency, biocompatibility, and flexibility, in addition to their moldability [4-10]. However, the other characteristics such as hydrophilicity and dielectric permittivity need to be tuned or improved for effective application of PDMS to the appropriate devices [11-13]. PDMS can be modified 
via polymer reactions or blending methods. These methods show a low degree of efficiency for the preparation of modified PDMS or give rise to deteriorate its own properties such as transparency and flexibility [14-16]. In order to avoid disadvantages of the platinum-catalyzed reaction or to form a designed pattern by using a mask or a direct laser, the photo-crosslinking reaction is used to solidify PDMS $[6,17,18]$.

In this study, we tried to enhance the dielectric property of a PDMS film even without deterioration in the other physical properties by substituting the hydridosilyl group-containing PDMS with vinyl acetate (VAc) as a crosslinker. The crosslinking reaction between the vinyl groups in PDMS and VAc is expected upon UV irradiation. Acetate moieties in VAc-grafted or -crosslinked PDMS can be converted to hydroxyl groups after saponification, resulting in improvement of the dielectric permittivity, as well as hydrophilicity, of PDMS. We know that the introduction of hydroxyl groups into nonpolar polymers improves their dielectric properties [19]. First of all, we examined the possibility of forming a film from the vinyl group-containing PDMS/VAc solution layer under UV curing. Further, we evaluated the electrical, mechanical, and optical properties of the UV-cured PDMS films before and after saponification.

\section{Methods}

\subsection{Synthesis of Poly(dimethylsiloxane-co-methylvinylsiloxane) (VPDMS)}

The copolymer was synthesized as shown in Scheme 1. Diethoxydimethylsilane (1) and diethoxymethylvinylsilane (2) were used as a comonomer. Amounts of $56.93 \mathrm{~g}(0.384 \mathrm{~mol}, 80 \mathrm{~mol} \%)$ of monomer 1 and $15.38 \mathrm{~g}(0.096 \mathrm{~mol}, 20 \mathrm{~mol} \%)$ of monomer 2 were used for the copolymerization. Next, $1.9 \mathrm{~mL}$ of $37 \%$ hydrochloric acid and $7.5 \mathrm{~mL}$ of distilled water were added to the monomers as a catalyst. The detailed polymerization condition, purification method, etc., are shown in our previous report [13]. Yield: $32.9 \mathrm{~g}(90 \%) . M_{n}=15.0 \times 10^{4} \mathrm{~g} / \mathrm{mol} . \mathrm{PDI}=1.66 . \mathrm{m}: \mathrm{n}$ (mole ratio) = 0.803:0.197. IR $v_{\max }\left(\mathrm{NaCl}\right.$ window, $\left.\mathrm{cm}^{-1}\right)$ : 1020s, 1093s (Si-O-Si str.); 1261s ( $\left(\mathrm{Si}-\mathrm{CH}_{3}\right.$ str.); 1408m, 1445w (C-H ben., methyl); 1598w (C=C str., vinyl); 2905m, 2963s (C-H str., methyl); 3055w (=C-H str., vinyl). ${ }^{1} \mathrm{H}$ NMR $\delta_{\mathrm{h}}\left(\mathrm{CDCl}_{3}, 500 \mathrm{MHz}\right): 0.12-0.19(9 \mathrm{H}, \mathrm{m}$, methyl); 5.82-5.87 (H, m, vinyl); 5.96-6.09 (2H, m, vinyl). ${ }^{13} \mathrm{C} \mathrm{NMR}_{\mathrm{c}}\left(\mathrm{CDCl}_{3}, 500 \mathrm{MHz}\right): 1.40-1.99\left(\mathrm{~m},-\mathrm{CH}_{3}\right) ; 133.44-133.57\left(\mathrm{~m},=\mathrm{CH}_{2}\right) ; 137.70(\mathrm{~m},-\mathrm{CH}=)$.

\subsection{Preparation of VPDMS Solutions in Vinyl Acetate and Film Fabrication}

After $1.0 \mathrm{~mol} \%$ of 1-hydroxycyclohexyl phenyl ketone was completely dissolved in vinyl acetate (VAc), the solution was uniformly mixed with VPDMS for 1 day. The VAc concentration was adjusted to ca. 10, 20, and $30 \mathrm{wt} \%$. The polymer solution was placed for a time in order to remove air bubbles formed during agitating. The VPDMS solution was poured on a glass plate and the solution layer was cast with a doctor's knife. The layer was UV-irradiated under nitrogen for $10 \mathrm{~min}$ and dried at $60^{\circ} \mathrm{C}$ under vacuum for $4 \mathrm{~h}$ to get rid of the unreacted VAc.

\subsection{Saponification of $U V$-Cured Film}

For preparation of an aqueous saponification solution, $8.0 \mathrm{~g}$ of sodium sulfate and $10.0 \mathrm{~g}$ of sodium hydroxide were dissolved in $100 \mathrm{~g}$ of a mixture of water and methanol (9:1, wt \%). After the UV-cured PDMS film was dipped into the saponification solution and treated at $40{ }^{\circ} \mathrm{C}$ for $24 \mathrm{~h}$ with stirring, it was thoroughly washed with water. Then, the film was vacuum-dried at $60^{\circ} \mathrm{C}$ for $4 \mathrm{~h}$.

The other experimental procedures are also explained in detail in the Supporting Information.

\section{Results and Discussion}

We synthesized poly(dimethylsiloxane-co-methylvinylsiloxane) (VPDMS) to introduce vinyl groups in poly(dimethylsiloxane) (PDMS) main chains, as shown in Scheme 1. We designed VPDMS to contain more methylvinylsiloxane moieties than the commercial PDMSs (Sylgard $184^{\mathrm{TM}}$, Elastosil P7670 ${ }^{\mathrm{TM}}$, and VDT $954^{\mathrm{TM}}$ ) do in order to enhance the possibility of crosslinking, as well as 
chemically attaching a vinyl- or acrylate-containing compound to the PDMS main chains [6]. We settled the amount of methylvinylsiloxane moiety at ca. $20 \mathrm{~mol} \%$. The VPDMS copolymer composition is estimated from the result of ${ }^{1} \mathrm{H}$ NMR spectroscopy (Figure S1b). We could calculate the copolymer composition by using the peak areas near 0 and $5.8-6.1 \mathrm{ppm}$. The former is designated to protons in $\mathrm{Si}-\mathrm{CH}_{3}$, and the latter to protons in the vinyl group. The calculated amount of methylvinylsiloxane moiety in the copolymer was $19.7 \mathrm{~mol} \%$, which nearly equals the feeding mole ratio. Even though the copolymer has a high molecular weight $\left(M_{n}\right.$, number-average molecular weight, $=15.0 \times 10^{4} \mathrm{~g} / \mathrm{mol}$ and $M_{\mathrm{w}}$, the weight-average molecular weight, $=24.9 \times 10^{4} \mathrm{~g} / \mathrm{mol}$ ), the transparent copolymer exhibits a highly viscous liquid state, as expected. The copolymer is well identified in Figure S1.

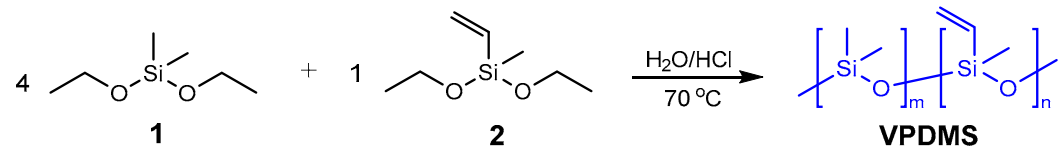

Scheme 1. Synthesis of poly(dimethylsiloxane-co-methylvinylsiloxane) (VPDMS).

We obtain homogenous VPDMS solutions in vinyl acetate (VAc) even if the difference of the solubility parameters between PDMS $\left(14.9 \sim 15.5 \mathrm{MPa}^{1 / 2}\right)$ and VAc $\left(18.4 \mathrm{MPa}^{1 / 2}\right)$ is comparatively large [20-22]. However, the solubility parameter value of VAc is calculated from the method of van Krevelen and Hoftyzer. The calculated value of PDMS from the method is $17.5 \mathrm{MPa}^{1 / 2}$ [22], which is closer to that of VAc. 1-Hydroxycyclohexyl phenyl ketone used as a photoinitiator could be fully activated under our UV power condition (Table S1) [23]. We optionally prepared three kinds of VPDMS solutions in which the content of VAc was settled at ca. 10, 20, and $30 \mathrm{wt} \%$ to identify a suitable condition for film formation during UV curing. Table 1 shows component ratios of the solutions in detail. We anticipate that VAc reacts with the methylvinylsiloxane moiety of VPDMS in the solution layer containing the photoinitiator upon UV irradiation, resulting in VAc-grafted or -crosslinked PDMS, as shown in Scheme 2. Films were well formed after UV curing in all cases, as expected. The film thickness was measured at ca. $200 \mu \mathrm{m}$. We know from Figure 1a that VAc was homopolymerized or reacted to VPDMS in the UV-cured films. The absorption peak appears near $1724 \mathrm{~cm}^{-1}$ due to the stretching vibration of the carbonyl group in poly(vinyl acetate) (PVAc) and increases in intensity as the VAc content rises. This peak does not come from the unreacted VAc because the VAc would be completely removed during the vacuum drying of the UV-cured film near the boiling point of VAc.

Table 1. Composition of VPDMS solutions in VAc and mechanical properties ${ }^{1}$ of the UV-cured films prepared from the solution layers.

\begin{tabular}{cccccc}
\hline $\begin{array}{c}\text { Name of Polymer } \\
\text { Solution }{ }^{2}\end{array}$ & $\begin{array}{c}\text { VPDMS } \\
(\mathbf{g})\end{array}$ & $\begin{array}{c}\mathrm{Vac}^{3} \\
\mathbf{( g )}\end{array}$ & $\begin{array}{c}\text { Initial } \\
\text { Modulus (kPa) }\end{array}$ & $\begin{array}{c}\text { Maximum } \\
\text { Stress (kPa) }\end{array}$ & $\begin{array}{c}\text { Maximum } \\
\text { Strain (\%) }\end{array}$ \\
\hline V10 & 4.02 & 0.55 & $220 \pm 19.0$ & $215 \pm 4.48$ & $141 \pm 15$ \\
& & & $353 \pm 25.7$ & $751 \pm 112$ & $320 \pm 30^{4}$ \\
V20 & 5.07 & 1.27 & $708 \pm 63.8$ & $119 \pm 22.9$ & $17.7 \pm 2.9$ \\
V30 & 3.99 & 1.71 & $943 \pm 200$ & $111 \pm 22.2$ & $12.1 \pm 3.7$ \\
\hline
\end{tabular}

${ }^{1}$ The values of mechanical properties were achieved from Figure $1 \mathrm{~b} .{ }^{2}$ A numeral of the solution names means wt $\%$ of VAc in each VPDMS solution. ${ }^{3}$ VAc contains $1.0 \mathrm{~mol} \%$ of 1-hydroxycyclohexyl phenyl ketone as a photoinitiator.

${ }^{4}$ The values are assigned to the mechanical properties of UV-cured film after saponification. 


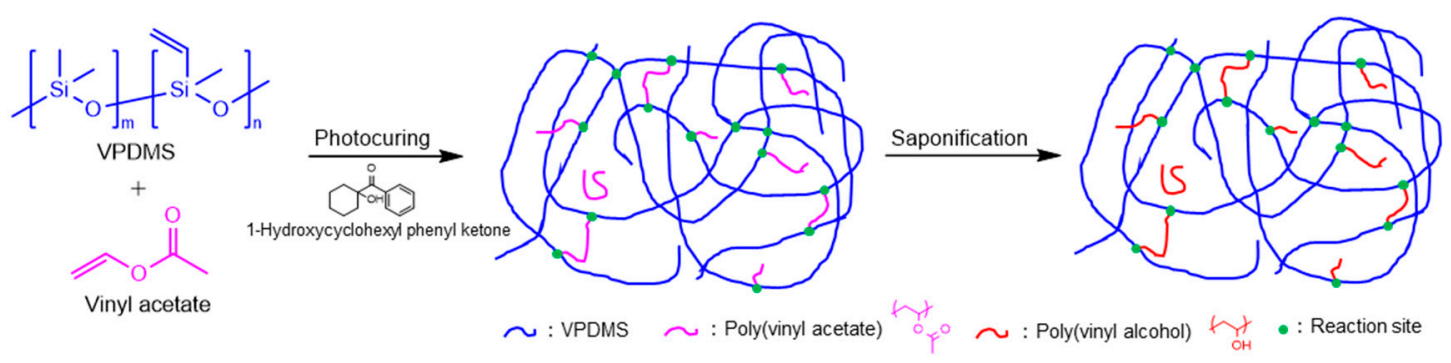

Scheme 2. Schematically depicted reaction of VPDMS with VAc during photocuring and saponification reaction of PVAc in the UV-cured film.

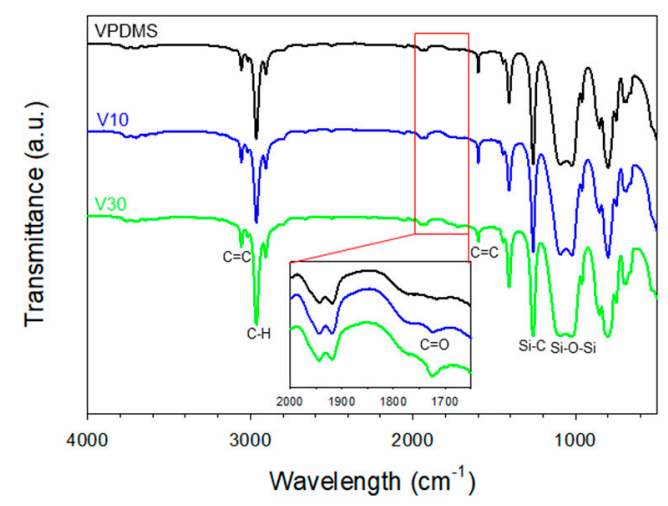

(a)

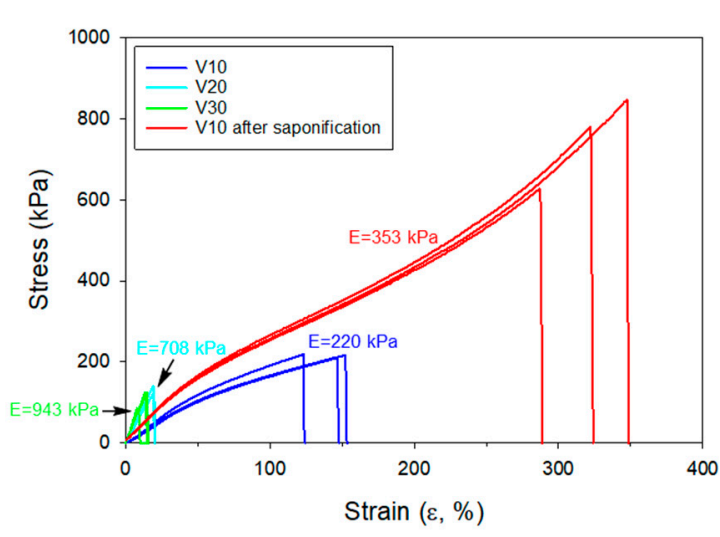

(b)

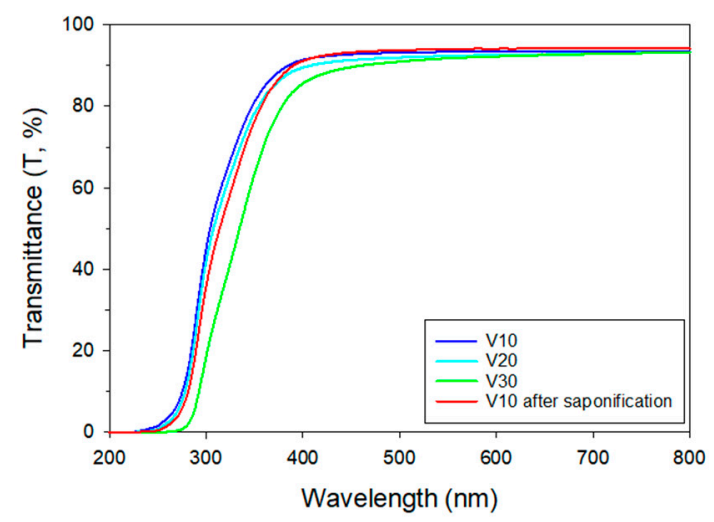

(c)

Figure 1. IR spectra of VPDMS and the films UV-cured from the V10 and V30 solution layers (a). Stress-strain curves (b) and transmittance spectra (c) of the films UV-cured from the V10, V20, and V30 solution layers and of the film UV-cured from the V10 solution layer after saponification, respectively.

Figure $1 \mathrm{~b}$ shows the stress-strain curves of the UV-cured films. The films UV-cured from the V20 and V30 solution layers seem quite brittle. This is because more VAc participated in the homopolymerization, as well as in the graft polymerization, to PDMS as the VAc content in the solution increased. Even if the vinyl acetate group is slowly homopolymerized in comparison to acrylate or vinyl groups under UV curing [24], VAc might be more homopolymerized as the VAc content increases, which affects the mechanical properties of the UV-cured films. Since the photoinitiator content in the VPDMS solution increases along with a rise in the VAc content, the vinyl groups of VPDMS react more with each other to result in additional crosslinking between the PDMS chains. This is because a photopolymerization rate is proportionate to the square root of a photoinitiator concentration $[25,26]$. 
The film UV-cured from the V10 solution layer was only enough for electromechanical actuation. In this case, VAc could be more grafted to VPDMS rather than be homopolymerized because the mole ratio of vinyl groups of VPDMS is higher than that of vinyl acetate groups in the solution, 0.62 . The mechanical properties of the UV-cured film from the V10 solution layer were lower than or nearly equivalent to those of the platinum-catalyzed hydrosilylation-cured PDMS films including the crosslinked films prepared from Sylgard $184^{\mathrm{TM}}$ and Elastosil $\mathrm{P} 7670^{\mathrm{TM}}$ via their suggested recipes (Figure S2a) [13]. The detailed property values of all the UV-cured films are summarized in Table 1. Even though VAc is homopolymerized during UV curing, the PVAc homopolymer could be well dispersed in the PDMS matrix due to the steady growth of compatibility between PVAc and PDMS-g-PVAc [27]. In addition, the refractive indices of PDMS and PVAc are similar, at 1.43 and 1.47 at a wavelength of $589 \mathrm{~nm}$, respectively [28]. Therefore, the UV-cured films show excellent transparency in a visible region $(T>90 \%)$, which is almost equal to that of the platinum-catalyzed hydrosilylation-cured PDMS (Figure 1c) [13]. The UV-cured film shows a bathochromic shift as the VAc content increases because the PVAc content increases in the film whether VAc is homopolymerized or grafted.

We saponified the films prepared from the V10 and V30 solution layers. The acetate groups in the UV-cured films would be converted to the hydroxyl groups via hydrolysis, as shown in Scheme 2. An aqueous saponification solution for the heterogenous reaction was prepared according to a previous report [29]. We used a sodium hydroxide and sodium sulfate solution in a mixture of water and methanol for the methanolysis of PVAc in our UV-cured films. The sodium hydroxide acts here as a catalysis for the methanolysis. The use of sulfate ion in the solution is for preventing the homopolymerized poly(vinyl alcohol) (PVA) in the UV-cured film from dissolving out into the saponification medium. For comparison of IR spectroscopy results before and after saponification of the film UV-cured from the V30 solution layer, we used an attenuated total reflection (ATR) method. After saponification of the UV-cured film, the absorption peak near $1724 \mathrm{~cm}^{-1}$ completely vanished because of the conversion of acetate groups to hydroxy groups (Figure 2a). We could not obviously find the absorption peak at $3200-3400 \mathrm{~cm}^{-1}$ designated to the $\mathrm{OH}$ stretching vibration that was expected from the converted PVA. However, we know that the peak in a heterogeneously saponified PVAc film is much less noticeable than that in a PVA film [30]. Therefore, the expected absorption peak in our saponified film may not markedly appear in the IR spectrum acquired especially from the ATR technique. The degree of saponification could not be quantitatively calculated for that reason. Nevertheless, our method of chemically or physically introducing water-soluble PVA into hydrophobic PDMS should be comparatively effective because they cannot be homogenously reacted or blended together due to their big difference in hydrophobicity $[10,31]$.

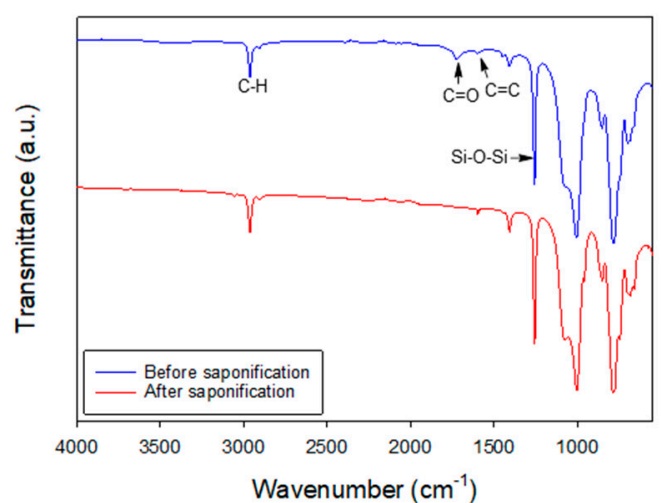

(a)

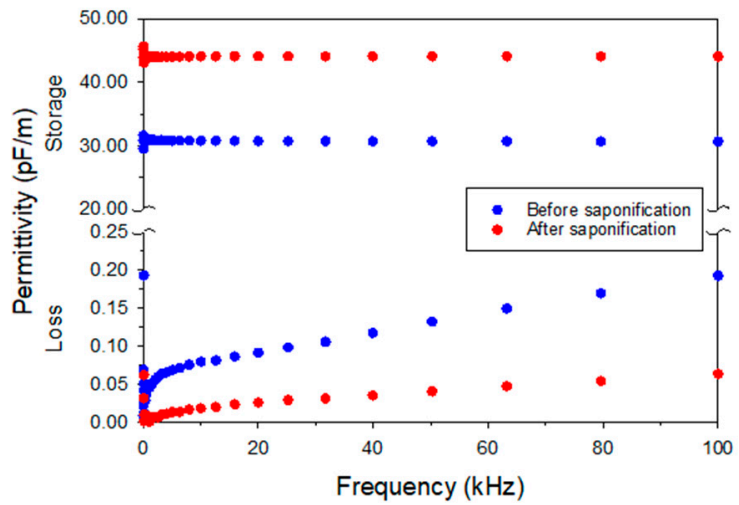

(b)

Figure 2. IR spectra of the UV-cured film fabricated from the V30 solution layer (a) and dielectric permittivity of the film from the V10 solution layer (b) before and after saponification. 
The thickness of UV-cured films was slightly reduced by ca. $10 \%$ after saponification because PVA is denser than PVAc. In addition, the homopolymerized PVA could be partly dissolved out in the saponification solution [29]. The UV-cured film prepared from the V10 solution became tougher after saponification, as shown in Figure 1b. It might be due to the hydrogen interaction between $\mathrm{OH}$ groups in the PVAs [32]. The initial modulus (E), maximum stress, and strain $(\varepsilon)$ values were increased from 220,215 , and $141 \%$ to $353 \mathrm{kPa}, 757 \mathrm{kPa}$, and $320 \%$, respectively. Figure $2 \mathrm{~b}$ exhibits that the storage permittivity $\left(\varepsilon^{\prime}\right)$ of the UV-cured film increased from 30.8 to $44.1 \mathrm{pF} / \mathrm{m}$ at $10 \mathrm{kHz}$ owing to growth of the dipole moment coming from the $\mathrm{OH}$ groups newly formed after saponification. The loss permittivity was also lessened below $0.05 \mathrm{pF} / \mathrm{m}$. E and $\varepsilon^{\prime}$ for the crosslinked films fabricated from Sylgard $184^{\mathrm{TM}}$ and Elastosil $\mathrm{P} 7670^{\mathrm{TM}}$ were measured at 800 and $159 \mathrm{kPa}$ and 26.9 and $25.4 \mathrm{pF} / \mathrm{m}$ at $10 \mathrm{kHz}$, respectively (Figure S2). Only the introduction of VAc into PDMS slightly improves the dielectric property. In the result, the UV-cured film, as well as the saponified film, might be superior to platinum-catalyzed hydrosilylation-cured PDMS films including the commercial PDMS as an electroactive polymer material because the actuation efficiency is proportional to $\varepsilon^{\prime}$ and inversely proportional to $\mathrm{E}[33,34]$. As another indirect evidence of the saponification reaction, we checked water contact angles of the UV-cured film surface before and after saponification. The contact angle was slightly decreased from $106.9^{\circ}$ to $102.0^{\circ}$ after saponification (Figure S3). The value is known to be ca. $110^{\circ}$ for Sylgard $184^{\mathrm{TM}}$ film [16]. The UV-cured film still showed very high transparency and a slight bathochromic shift after saponification (Figure 1c).

\section{Conclusions}

We developed a UV-cured poly(dimethylsiloxane) (PDMS) film with high dielectric and optical properties, as well as a low initial modulus. We introduced a lot of vinyl groups into PDMS and prepared the PDMS solutions in vinyl acetate (VAc) in order to achieve a crosslinked PDMS film containing hydroxyl groups. As designed, films were simply prepared by photocuring of the solution layers and VAc was chemically attached and grafted to PDMS through the curing process. One of the UV-cured PDMS films exhibited a low initial modulus and improved storage permittivity, along with high transparency. Saponification led the acetate groups to convert the hydroxyl groups in the UV-cured film, resulting in a rise in the initial modulus and strain, as well as storage permittivity, of the film. The UV-cured PDMS film, whether saponified or not, is more advantageous than platinum-catalyzed hydrosilylation-cured PDMS films to apply to dielectric elastomer actuators in terms of not only electromechanical actuation but also the fabrication process. In a continuation of our work, we will examine the potentiality of using the UV-cured elastomer as an electroactive polymer.

Supplementary Materials: The following are available online at http://www.mdpi.com/2073-4360/12/11/2660/s1, Figure S1: IR (a), ${ }^{1} \mathrm{H}-\mathrm{NMR}$ (b), ${ }^{13}$ C-NMR (c), and GPC (d) spectra of VPDMS, Figure S2: Stress-strain curves (a) and dielectric permittivity (b) of the PDMS films prepared from Sylgard $184^{\mathrm{TM}}$ and Elastosil P7670 ${ }^{\mathrm{TM}}$, Figure S3: Water contact angles of the UV-cured film prepared from the V10 solution before (a) and after (b) saponification, Table S1: UV lamp intensity applied on the solution layers.

Author Contributions: S.K.P. planned this research; B.J.P. and S.K.P. designed the methodology; M.C., E.J.S., D.W.K. and S.K.P. conducted the experiments; D.W.K. and S.K.P. analyzed the collected data; S.K.P. wrote the draft document; D.W.K. and S.P. reviewed the document; S.P. and S.Y. organized this project. All authors have read and agreed to the published version of the manuscript.

Funding: This work has been supported by an Electronics and Telecommunications Research Institute (ETRI) grant funded by the Korean government (20ZS1200, Fundamental Technology Research for Human-Centric Autonomous Intelligent Systems).

Acknowledgments: The authors thank Joo Yeon Kim (ETRI) for the measurement of the water contact angle.

Conflicts of Interest: The authors declare no conflict of interest. 


\section{References}

1. Mark, J.E. Some interesting things about polysiloxanes. Acc. Chem. Res. 2004, 37, 946-953. [CrossRef] [PubMed]

2. Zheng, P.; McCarthy, T.J. Rediscovering silicones: Molecular smooth, low surface energy, unfilled, UV/Vis-transparent, extremely crosslinked, thermally stable, hard, elastic PDMS. Langmuir 2010, 26, 18585-18590. [CrossRef] [PubMed]

3. Speier, J.L.; Webster, J.A.; Barnes, G.H. The addition of silicone hydrides to olefinic double bonds. Part II. The use of group VIII metal catalysts. J. Am. Chem. Soc. 1957, 79, 974-979. [CrossRef]

4. Hirota, K.; Hara, S.; Wada, H.; Shimojima, A.; Kuroda, K. Fabrication of uniaxially aligned silica nanogrooves with sub-5 nm periodicity on centimeter-scale Si substrate using poly(dimethylsiloxane) stamps. ACS Nano 2019, 13, 2795-2803. [CrossRef] [PubMed]

5. Zhang, Z.; Zhao, S.; Hu, F.; Yang, G.; Li, J.; Tian, H.; Peng, N. An LED-driven AuNPs-PDMS microfluidic chip and integrated device for the detection of digital loop-mediated isothermal DNS amplification. Micromachines 2020, 11, 177. [CrossRef]

6. Tsougeni, K.; Tserepi, A.; Gogolides, E. Photosensitive poly(dimethylsiloxane) materials for microfluidic applications. Microelectron. Eng. 2007, 84, 1104-1108. [CrossRef]

7. Kang, H.; Zhao, C.; Huang, J.; Ho, D.H.; Megra, Y.T.; Suk, J.W.; Sun, J.; Wang, Z.L.; Sun, Q.; Cho, J.H. Fingerprint-inspired conducting hierarchical wrinkles for energy-harvesting E-skin. Adv. Funct. Mater. 2019, 29, 1903580. [CrossRef]

8. Wang, D.; Sheng, B.; Peng, L.; Huang, Y.; Ni, Z. Flexible and optical fiber sensors composited by graphene and PDMS for motion detection. Polymers 2019, 11, 1433. [CrossRef]

9. Mun, S.; Yun, S.; Nam, S.; Park, S.K.; Park, S.; Park, B.J.; Lim, J.M.; Kyung, K.-U. Electro-active polymer based soft tactile interface for wearable devices. IEEE Trans. Haptics 2018, 11, 15-21. [CrossRef]

10. Wolf, M.P.; Salieb-Beugelaar, G.B.; Hunziker, P. PDMS with designer functionalities-properties, modifications strategies, and applications. Prog. Polym. Sci. 2018, 83, 97-134. [CrossRef]

11. Emah, J.B.; George, N.J.; Akpan, U.B. Interfacial surface modification via nanoimprinting to increase open-circuit voltage of organic solar cells. J. Electron. Mater. 2017, 46, 4989-4998. [CrossRef]

12. Chuah, Y.J.; Koh, Y.T.; Lim, K.; Menon, N.V.; Wu, Y.; Kang, Y. Simple surface engineering of polydimethylsiloxane with polydopamine for stabilized mesenchymal stem cell adhesion and multipotency. Sci. Rep. 2015, 5, 18162. [CrossRef] [PubMed]

13. Park, S.K.; Park, B.J.; Choi, M.J.; Kim, D.W.; Yoon, J.W.; Shin, E.J.; Yun, S.; Park, S. Facile functionalization of poly(dimethylsiloxane) elastomer by varying content of hydridosilyl groups in a crosslinker. Polymers 2019, 11, 1842. [CrossRef] [PubMed]

14. Lee, Y.J.; Caspari, P.; Opris, D.M.; Nüesch, F.A.; Ham, S.; Kim, J.-H.; Kim, S.-R.; Ju, B.-K.; Choi, W.K. Electrical energy generated by silicone elastomers filled with nanospring-carbon-nanotubes. J. Mater. Chem. C 2019, 7, 3535-3542. [CrossRef]

15. Quinsaat, J.E.Q.; Alexandru, M.; Nüesch, F.A.; Hofmann, H.; Borgschulte, A.; Opris, D.M. Highly stretchable dielectric elastomer composites containing high volume fractions of silver nanoparticles. J. Mater. Chem. A 2015, 3, 14675-14685. [CrossRef]

16. Dirany, M.; Dies, L.; Restagno, F.; Léger, L.; Poulard, C.; Miquelard-Garnier, G. Chemical modification of PDMS surface without impacting the viscoelasticity: Model systems for a better understanding of elastomer/elastomer adhesion and friction. Colloid Surf. A-Physicochem. Eng. Asp. 2015, 468, 174-183. [CrossRef]

17. Goswami, K.; Skov, A.L.; Daugaard, A.E. UV-cured, platinum-free, soft poly(dimethylsiloxane) networks. Chem. Eur. J. 2014, 20, 9230-9233. [CrossRef]

18. Obata, K.; Slobin, S.; Schonewille, A.; Hohnholz, A.; Unger, C.; Koch, J.; Suttmann, O.; Overmeyer, L. UV laser direct writing of 2D/3D structures using photo-curable polydimethylsiloxane. Appl. A-Mater. Sci. Process. 2017, 123, 495. [CrossRef]

19. Abd-El-Messieh, S.L.; Mohamed, M.G.; Mazrouaa, A.M.; Soliman, A. Dielectric investigation of some normal alcohols and diols dispersed in some polymeric matrices. J. Appl. Polym. Sci. 2002, 85, 271-281. [CrossRef]

20. Lee, J.N.; Park, C.; Whitesides, G.M. Solvent compatibility of poly(dimethylsiloxane)-based microfluidic devices. Anal. Chem. 2003, 75, 6544-6554. [CrossRef] 
21. Grulke, E.A. Solubility parameter values. In Polymer Handbook, 4th ed.; Brandrup, J., Immergut, E.H., Grulke, E.A., Eds.; John Wiley \& Sons: New York, NY, USA, 1999; Volume 2, pp. 675-714.

22. Van Krevelen, D.W.; Hoftyzer, P.J. Practical evaluation of the [ $\eta]-M$ relationship. III. Estimation of the exponent a. J. Appl. Polym. Sci. 1967, 11, 2189-2200. [CrossRef]

23. Photoinitiators for UV Curing. Available online: https://people.rit.edu/deeemc/reference_13/Imprint/ Photoinitiators\%20for\%20UV\%20curing.pdf/ (accessed on 8 August 2020).

24. Lee, T.Y.; Roper, T.M.; Jonsson, E.S.; Kudyakov, I.; Viswanathan, K.; Nason, C.; Guymon, C.A.; Hoyle, C.E. The kinetics of vinyl acrylate photopolymerization. Polymer 2003, 44, 2859-2865. [CrossRef]

25. Andrzejewska, E. Photopolymerization kinetics of multifunctional monomers. Prog. Polym. Sci. 2001, 26, 605-665. [CrossRef]

26. Park, S.K.; Kwark, Y.-J.; Moon, J.; Joo, C.W.; Yu, B.; Lee, J.-I. Finely formed, kinetically modulated wrinkle structures in UV-crosslinkable liquid prepolymers. Macromol. Rapid Commun. 2015, 36, 2006-2011. [CrossRef] [PubMed]

27. Deanin, R.D.; Manion, M.A. Compatibilization of polymer blends. In Polymer Blends and Alloys; Shonaike, G.O., Simon, G.P., Eds.; Marcel Dekker: New York, NY, USA, 1999; pp. 1-22.

28. Seferis, J.C. Refractive indices of polymers. In Polymer Handbook, 4th ed.; Brandrup, J., Immergut, E.H., Grulke, E.A., Eds.; John Wiley \& Sons: New York, NY, USA, 1999; Volume 2, pp. 571-582.

29. Lee, S.G.; Kim, J.P.; Kwon, I.C.; Park, K.H.; Noh, S.K.; Han, S.S.; Lyoo, W.S. Heterogeneous surface saponification of suspension polymerized monodisperse poly(vinyl acetate) microspheres using various ions. J. Polym. Sci. Pol. Chem. 2006, 44, 3567-3576. [CrossRef]

30. Yang, S.B.; Yoo, S.H.; Lee, J.S.; Kim, J.W.; Yeum, J.H. Surface properties of a novel poly(vinyl alcohol) film prepared by heterogeneous saponification of poly(vinyl acetate) film. Polymers 2017, 9, 493. [CrossRef]

31. Choi, S.-J.; Kwon, T.-H.; Im, H.; Moon, D.-I.; Baek, D.J.; Seol, M.-L.; Duarte, J.P.; Choi, Y.-K. A polydimethylsiloxane (PDMS) sponge for the selective absorption of oil from water. ACS Appl. Mater. Interfaces 2011, 3, 4552-4556. [CrossRef]

32. Dai, L.; Yu, S. Effect of degree of saponification on structural and property change of poly(vinyl alcohol) fibers. Polym. Adv. Technol. 2003, 14, 449-457. [CrossRef]

33. Pelrine, R.; Kornbluh, R.; Pei, Q.; Joseph, J. High-speed electrically actuated elastomers with strain greater than $100 \%$. Science 2000, 287, 836-839. [CrossRef]

34. White, B.T.; Long, T.E. Advances in polymeric materials for electromechanical devices. Macromol. Rapid Commun. 2019, 40, 1800521. [CrossRef]

Publisher's Note: MDPI stays neutral with regard to jurisdictional claims in published maps and institutional affiliations.

(C) 2020 by the authors. Licensee MDPI, Basel, Switzerland. This article is an open access article distributed under the terms and conditions of the Creative Commons Attribution (CC BY) license (http://creativecommons.org/licenses/by/4.0/). 